\title{
Depression Status Decreased Quality of Life Among Postpartum Mother
}

\author{
Lastri Mei Winarni ${ }^{1}$ \\ ${ }^{1}$ Lecturer of Midwifery at STIKes Yatsi Tangerang, Banten, Indonesia \\ meidilastri@gmail.com \& lastri@stikesyatsi.ac.id \\ *Corresponding author
}

Submission date: 16 Februari 2021, Receipt date: 20 Maret 2021, Publication date: 1 April 2021

\section{Abstract}

The purpose of this study was to know correlation between depression symptoms and the quality of life (QoL) among postpartum mother. Method of the study was used quasi experimental design by pre and post test with control group. The respondents are 54 mothers. The study was conducted at maternal clinic. Statistical analysis used Pearson and simple linear regression. Result of the study there is correlation between depression symptoms and the QoL among postpartum mothers with $r$ count values $<r$ table values $(0.030<0.05)$. The correlation direction was negative, the higher depression symptoms, the -0.296 times the QoL of mothers decreased.

Keywords: maternal psychological conditions, postpartum mothers, quality of life for mothers

\section{INTRODUCTION}

Quality of life in postpartum mothers is very important to be considered by health workers such as midwives, nurses, and doctors, and not to mention life partners, close family, neighbors, coworkers, and friends(Papamarkou et al. 2017; Winarni, Ikhlasia, and Sartika 2020). Some studies explained that postpartum period can change the quality of life among mothers caused by changes in physical, psychological, social and environmental conditions(Papamarkou et al. 2017; Zubaran and Foresti 2011). Postpartum period is a period of physical recovery from the fatigue of labor. The mother's body will also experience a process of physiological adaptation to restore the body's organs back to pre-pregnancy. In addition, it will also lead to emotional and social changes. As a result, it may affect quality of life for postpartum mothers(Martínez-Galiano et al. 2019; Zubaran and Foresti 2011).

Quality of life is an indicator to measure public health status, perceptions of individual views about their position in life, ability to carry out daily tasks, culture, value systems, which are adjusted to the goals, expectations, standards, and concerns of the individuals(Rezaei et al. 2018; Sadat, Abedzadeh-kalahroudi, and Atrian 2014; Tungchama et al. 2017). It is not a standard of living of people which is only measured by income, but rather the function of welfare, ability to work or do activities, physical and emotional health, recreation, education, and social relations(Kohler et al. 2018). In this 
study, the quality of life of postpartum mothers is defined as satisfaction, wellbeing and perceptions of life, psychological conditions and happiness experienced by mothers during the postpartum period (Gharacheh, Ranjbar, and Azadi 2018). The quality of life of a mother can be affected by physical, psychological health conditions, social relations, level of independence, personal trust, and environment(Tungchama et al. 2017).

Studies on the quality of life for postpartum mothers in Indonesia are few; thus, it is still difficult to obtain clarity about how the quality of life for postpartum mothers. However, in 2018, the quality of human life in Indonesia increased $0.82 \%$ to 71.39 from the previous year. Quality of life for postpartum mothers is influenced by various factors, including maternal physical condition, psychological conditions, social relations, environment, age, concomitant diseases during pregnancy, type of labor, education, maternal knowledge, parity, socioeconomic status, delivery complications, and social support(Papamarkou et al. 2017; Winarni et al. 2020). Mothers who experience low quality of life since pregnancy have the potential to experience low quality of life also during postpartum (Jeong et al. 2021; Rezaei et al. 2018).

Maternal psychological condition in the postpartum period is an important part to overcome because it is related to the mental health status of the mother and baby in the future (Aurpibul et al. 2020). Mood disorders such as sadness, worry, sensitivity and anger are often experienced by $50-80 \%$ of mothers in the postpartum period (Batt et al. 2020; Zubaran and Foresti 2011). This psychological disorder can last up to 4-6 months of postpartum (Daglar, Bilgic, and Aydın \&amp;Ouml;zkan 2018). Zubaran et al. reported that there were $14.5 \%$ who had major or minor postpartum depression experienced disorders for three months of postpartum. In the postpartum period, if the mother does not get a coping mechanism in dealing with these mild psychological disorders, the mother can potentially experience postpartum depression(Smorti, Ponti, and Pancetti 2019; Zubaran and Foresti 2011). Several studies in Australia explain that the mother has begun to show symptoms of decreased quality of life during pregnancy, especially in the aspects of psychological conditions, and this will continue until the postpartum period. Similarly, studies in Sweden show that the quality of life scores of postpartum mothers decreased in physical condition, disease resistance, and their health focus(Martínez-Galiano et al. 2019).

Postpartum depression is a mental health disorder that is often experienced by mothers after childbirth (Anokye et al. 2018; Stewart and Vigod 2019). This disorder is characterized by feelings of depression, weakness, disappointment, psychological pressure, inability to feel happiness, sleep disturbance, disruption of nutritional patterns and daily activities (Reay et al. 2011; Sadat et al. 2014). Predisposing factors that cause postpartum depression are mental disorders, depression during pregnancy, low socioeconomic status, psychological disorders that are not handled properly at the beginning of the puerperium, the quality of marital relationships, family problems, complications of the disease, 
and lack of maternal access to health services(Do, Nguyen, and Pham 2018; Edhborg, Nasreen, and Kabir 2011).

Some studies explain that thre is a close correlation between postpartum depression and maternal quality of life. For example, Tungchama et al. explained that mothers who experience postpartum depression will experience a decrease in quality of life compared to postpartum mothers who do not experience postpartum depression. Mothers who experience postpartum depression can have a delay in their baby's physical, intelligence, and social development.(Papamarkou et al. 2017; Tungchama et al. 2017) Mothers who experience postpartum depression will also have difficulty caring for themselves, babies, and their families, and have low attention to the growth and development of infants, immunization schedules, reduced interest in breastfeeding, problems communicating with partners, and difficulties undergoing the role of being a new mother (Anokye et al. 2018; Do et al. 2018; Silva et al. 2017). This will certainly have a long-term impact on the quality of life of the mother, the survival of the family, and the growth and development of her baby. Therefore, researchers are interested in analyzing the effect of depression symptoms in postpartum mothers on their quality of life.

\section{RESEARCH METHODS}

Correlation study was used to determine the causal relationship between depression symptoms and quality of life among postpartum mothers. The analysis used a simple regression to examine the extent of the effect of depression symptoms on quality of life among postpartum mothers. This research involved midwives in the independent practice and two first-level health facilities in Tangerang in May-August 2019. The population of this study was 61 mothers of one to six weeks of postpartum, in which the sample was determined using a total sampling technique. The respondents who completed and submitted the questionnaire were 54 mothers. The inclusion criteria of the respondents were mothers giving birth one to six weeks of postpartum, and willing to fill out a questionnaire. The exclusion criteria of the respondents are the respondents who did not complete the questionnaire.

The instrument used in this study was a questionnaire measuring the depression symptoms in postpartum mothers using the Edinburgh Postnatal Depression Scale (EPDS) and a quality of life questionnaire from The World Health Organization's Quality of Life (WHOQOL-BREF). The WHOQOLBREF questionnaire has 26 questions consisting of four dimensions namely physical dimensions (Q3, Q4, Q10, Q15, Q16, Q17, Q18), psychological dimensions (Q5, Q6, Q7, Q11, Q19, Q26), social dimensions (Q20, Q21, Q22), and environmental dimensions (Q8, Q9, Q12, Q13, Q14, Q23, Q24, Q25). The quality of life questionnaire uses formal Bahasa Indonesia with Indonesian version of WHOQO-BREF with The reliability of the questionnaire was assessed by the intraclass correlation coefficient for each domain of 0.401-0.484 and the Cronbach Alpha value of 0.513-0.798 (Muhammad et al. 2017), while the EPDS questionnaire consists of 10 questions regarding the measurement of the psychological condition of postpartum mothers who have a sensitivity value 
of $80 \%$ and a specificity of $78 \%$. Construct validity in relation with HSCL-25 with correlation coefficient 0.51 (los $<0.01)$. Single test reliability was acceptable (Coefficient $\alpha=0.652$ ). It shows that The EPDS is a valid and reliable instrument to be used as a screening instrument for postnatal depression in Indonesia (Hutauruk 2011).

This study has passed the ethical test from the Ethics Committee of STIKes Yatsi No. 253/LPPM-STIKESYYATSI/IV/2019.

Data processing used the process of coding, editing, tabulating and analyzing data. Analysis using the Kolmogorov-Smirnof normality test shows that the data were normally distributed. Meanwhile, univariate and bivariate analyses used Pearson Correlation and simple linear regression analyses.

The following results were obtained:

\section{RESULTS AND DISCUSSION}

Table 1. Characteristics of Postpartum Mothers in Tangerang $(n=54)$

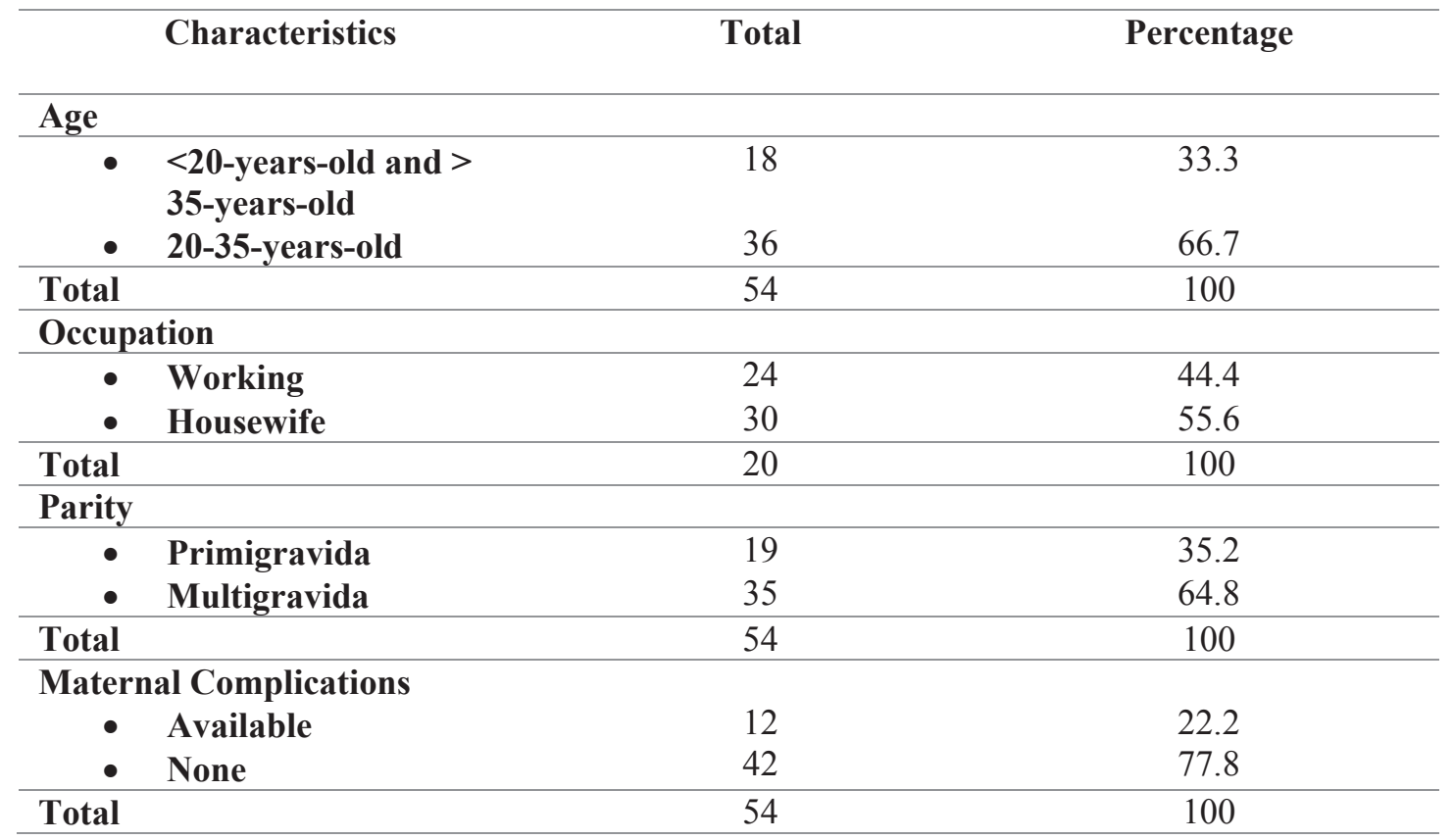

Based on table 1 it is known that the characteristics of postpartum mothers $33.3 \%$ have age at risk, namely $<20$ years and $>35$ years, $55.6 \%$ of mothers are housewives, $64.8 \%$ have mothers with multigravida status, and $77.8 \%$ of mothers do not experience complications at delivery and puerperal. 
Table 2. Frequency Distribution of Symptoms of Depression Symptoms and Quality of Life of Postpartum Mothers $(n=54)$

\begin{tabular}{lcccccc}
\hline \multicolumn{1}{c}{ Variable } & Mean & Median & SD & Min-Max & $\begin{array}{c}\text { Pearson } \\
\text { Correlation }\end{array}$ & $\begin{array}{c}\text { Sig. (2- } \\
\text { tailed) }\end{array}$ \\
\cline { 1 - 3 } $\begin{array}{l}\text { Depression } \\
\text { Symptoms }\end{array}$ & 8.15 & 8 & 1.55 & $5-12$ & -0.296 & .030 \\
$\begin{array}{l}\text { Quality of Life } \\
\text { for Mothers }\end{array}$ & 75.23 & 75 & 2.85 & $70-83$ & & \\
\hline
\end{tabular}

\begin{tabular}{|c|c|c|c|c|c|c|}
\hline \multicolumn{7}{|c|}{ Coefficients $^{a}$} \\
\hline & & \multicolumn{2}{|c|}{ Unstandardized Coefficients } & $\begin{array}{l}\text { Standardized } \\
\text { coefficients }\end{array}$ & & \\
\hline \multicolumn{2}{|c|}{ Models } & $\mathrm{B}$ & Std. Error & Beta & $t$ & Sig. \\
\hline \multirow[t]{2}{*}{1} & (Constant) & 79.725 & 2.024 & & 39.387 & .000 \\
\hline & Depression Symptoms & -.546 & 244 & -.296 & -2.236 & .030 \\
\hline
\end{tabular}

a. Dependent Variable: Maternal Quality of Life

Table 2 shows that the average value of depression symptoms among mothers was 8.15 , and the average value of quality of life for mothers was 75.23. Then, the value of Sig.2 (tailed) between the depression symptoms and quality of life for postpartum mothers was $0.030<0.05$, indicating a significant correlation. The value of $r$ count $-0.296<0.2221$; thus, there was a correlation between depressive symptoms and the quality of life among postpartum mothers. The correlation direction was negative, meaning the higher the depression symptoms, the 0.296 times the quality of life of postpartum mothers decreased.

It is known that the coefficient of determination was $8.8 \%$, indicating the depression symptoms contributed $8.8 \%$ to the maternal quality of life, while the other $91.2 \%$ was influenced by other factors outside the depression symptoms. The value of Sig. of this regression analysis was $0.030<0.05$, meaning this linearity regression model met the criteria for linearity. The formed regression equation model is $\mathrm{Y}=79.725+(-0.546) \mathrm{X} 1$

Based on the results of this study, it was found that mothers who had signs and symptoms of postpartum depression $(>10)$ had a lower quality of life value than women who did not have signs of postpartum depression symptoms $(<10)$. This is in line with Tungchama's research stating that mothers who experience postpartum depression have lower perceptions about their quality of life than mothers who do not experience postpartum depression (Tungchama et al. 2017). Research in Taiwan shows that postpartum depression rates are quite high at $27.8 \%$ as measured by the Edinburgh Postnatal Depression Scale (EPDS), commonly experienced by mothers who have a history of diabetes mellitus, uterine infections or hypertension (Do et al. 2018). Most mothers who 
experience postpartum depression have poor communication with a partner or family. Diseases experienced by mothers can reduce the quality of life of mothers in terms of physical conditions (Mousavi and Shojaei 2021). Even, poor communication will reduce the support of partners and their families. Mothers who experience postpartum depression symptoms showed insecurities (feelings of insecurity) in themselves, affecting self-concepts and perceptions about the quality of life (Nakamura et al. 2020). This insecurity can cause a mother to feel guilty because she has not been a good mother to her baby, or a good wife to her husband. This made the mother's self-confidence become low and interferes with her new role as a mother who is responsible for caring for herself, her baby and maintaining her relationship with the family(Badr 2017; Tungchama et al. 2017). Various things that need to be paid attention by postpartum mothers include postpartum control period, baby's immunization schedule, nutritional needs for healing postpartum injuries and breastfeeding, bonding attachments, and the growth and development of the baby. Meanwhile, mothers whose symptoms of depressive symptoms were $<10$, they were easier to feel a better quality of life. There was a change in their physical condition, however, they were willing to do various things to help recover, for example by meeting their nutritional needs, physical activities such as puerperal gymnastics, yoga, and schedule a control at a health service facility, either doctor's examination or a midwife to monitor her physical health during childbirth(Ay 2018; Winarni et al. 2020). The emotional state changes, however, mothers who had good mental health they could communicate it to their spouse (husband) or family and close friends(Shitu, Geda, and Dheresa 2019). They were not reluctant to ask for help, social and emotional support to meet the emptiness, sadness, disappointment experienced during the postpartum period. This would help improve the quality of life of the mother in the postpartum period, which began with positive activities related to her physical condition, openness about the feelings and emotions of the mother. Those would have a more positive impact on both social and environmental aspects (Mousavi and Shojaei 2021).

The regression model found in this study illustrates the negative position in mothers who had depression symptoms on their quality of life. This is in line with research in Australia and Sweden stating that mothers who experience postpartum depression will reduce their quality of life in the aspects of physical, psychological, social and environmental health conditions. However, the study of Tungchama et al. stated that postpartum depression affects a decrease in the quality of life of postpartum mothers in physical and emotional health aspects; whereas, in social and environmental aspects, there is no visible decrease(Edhborg et al. 2011; Tungchama et al. 2017; Zubaran and Foresti 2011). Therefore, several models of postpartum maternal care were developed to address depression symptoms that arise during the postpartum period, e.g. increasing education to mothers and families about postpartum depression given during the third trimester of pregnancy, or information about postpartum depression symptoms given to husbands or family before the mother leaves the health service after her midwifery care is complete, or periodic comprehensive 
monitoring at one week, two weeks, up to six weeks of postpartum, and early detection for mothers found postpartum symptoms with a value $>10$ on the Edinburgh Postnatal Depression Scale questionnaire (EPDS).

The results of this study show that postpartum mothers commonly showed depression symptoms with a value of 8.15 which was perceived as no signs of severe postpartum depression symptoms. However, the maximum value found was 12, meaning some mothers experienced signs of postpartum depression symptoms that required further monitoring and treatment from health workers both midwives and nurses. This is consistent with the research of Zubaran et al. who stated that the mothers with postpartum depression was between 15-20\% (Department of Mental Health and Substance. World Health Organization 2016; Martínez-Galiano et al. 2019; Sadat et al. 2014), and this will be triple in developing countries. Research on the effects of postpartum depression on quality of life can help health workers and the community to add information about appropriate care for postpartum mothers and improve their well-being(Abdollahi and Zarghami 2019; Feki et al. 2017).

The weakness of this study is that respondents who filled out the questionnaire were mothers in one to six weeks of postpartum, while postpartum depression can occur up to the twelfth week of postpartum. Therefore, health workers, couples, and families need to actively monitor the health condition of postpartum mothers in terms of physical, psychological, social and environmental aspects. Thus, early detection of postpartum depression symptoms needs to be given to the mother, partner and family before the postpartum mothers leave the hospital. Postpartum visits (KF1, KF2, KF3) need to be carried out comprehensively to assess the physical, psychological, social and environmental conditions related to the quality of life among postpartum mothers.

Early detection of mothers and early treatment to overcome postpartum depression needs to be given and strengthened to health workers, especially midwives and nurses, because this will improve the quality of life for postpartum mothers and overcome problems that occur in mothers who have signs and symptoms of postpartum depression.

\section{CONCLUSION}

There was a correlation between depression symptoms and quality of life among postpartum mothers. Postpartum mothers who experienced depression symptoms will decrease -0.296 quality of life compared to women who did not experience depression symptoms in the postpartum period. Therefore, efforts to prevent and detect early signs of postpartum depression symptoms need to be done by health workers. Health education regarding depression symptoms during postpartum needs to be informed to the spouse or family when postpartum mothers leave health services. 


\section{REFERENCES}

Abdollahi, F., and M. Zarghami. 2019. "Quality of Life and Related Factors in

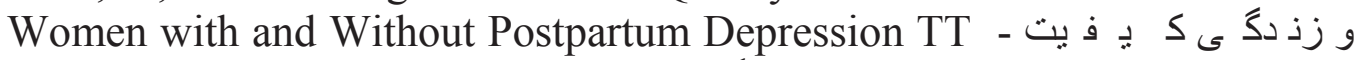

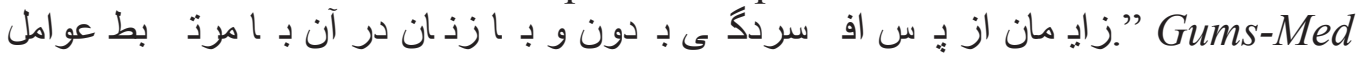
28(109):1-12.

Anokye, Reindolf, Enoch Acheampong, Amy Budu-Ainooson, Edmund Isaac

Obeng, and Adjei Gyimah Akwasi. 2018. "Prevalence of Postpartum

Depression and Interventions Utilized for Its Management." Annals of General Psychiatry 17(1):1-8.

Aurpibul, Linda, Fuanglada Tongprasert, Uraiwan Wichasilp, and Arunrat Tangmunkongvorakul. 2020. "Depressive Symptoms Associated with Low Quality of Life Among Pregnant and Postpartum Women Living with HIV in Chiang Mai, Thailand." International Journal of Maternal and Child Health and AIDS (IJMA) 9(3):421-29.

Ay, Fatma. 2018. "Postpartum Depression and the Factors Affecting It: 20002017 Study Results." Journal of Psychiatric Nursing 9(3):147-52.

Badr, Hanan E. 2017. "Postpartum Depression and Health Related Quality of

Life: A Necessary Assessment." International Journal of Family \& Community Medicine 1(1):11-17.

Batt, Melissa M., Korrina A. Duffy, Andrew M. Novick, Christina A. Metcalf, and C. Neill Epperson. 2020. "Is Postpartum Depression Different From Depression Occurring Outside of the Perinatal Period? A Review of the Evidence." Focus 18(2):106-19.

Daglar, Gulseren, Dilek Bilgic, and Semiha Aydın \&amp;Ouml;zkan. 2018. "Depression, Anxiety and Quality of Life of Mothers in the Early Postpartum Period." International Journal of Behavioral Sciences 11(4):152-59.

Department of Mental Health and Substance. World Health Organization. 2016. Improving Maternal Mental Health.

Do, Thi Kim Ly, Thi Thanh Huong Nguyen, and Thi Thu Huong Pham. 2018. "Postpartum Depression and Risk Factors among Vietnamese Women." BioMed Research International 2018:4028913.

Edhborg, Maigun, Hashima-E. Nasreen, and Zarina Nahar Kabir. 2011. "Impact of Postpartum Depressive and Anxiety Symptoms on Mothers' Emotional Tie to Their Infants 2-3 Months Postpartum: A Population-Based Study from Rural Bangladesh." Archives of Women's Mental Health 14(4):307.

Feki, R., I. Feki, D. Trigui, I. Baâti, R. Sallemi, and J. Masmoudi. 2017. "Impact of Postpartum Depression on Quality of Life." European Psychiatry 41(S1):s901-2.

Gharacheh, M., F. Ranjbar, and S. Azadi. 2018. "Women's Quality of Life and

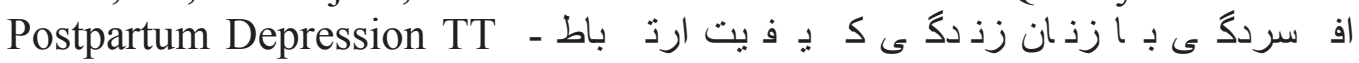

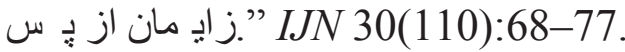

Hutauruk, I. 2011. "Indonesian Version of the Edinburgh Postnatal Depression 
Scale: Cross-Cultural Adaptation and Validation.” Jurnal Ilmiah Psikologi Gunadarma 5(2):98480.

Jeong, Yu Jeong, Ju Hee Nho, Hye Young Kim, and Ji Young Kim. 2021. "Factors Influencing Quality of Life in Early Postpartum Women." International Journal of Environmental Research and Public Health 18(6):1-9.

Kohler, Stefan, Kristi Sidney Annerstedt, Vishal Diwan, Lars Lindholm, Bharat Randive, Kranti Vora, and Ayesha De Costa. 2018. "Postpartum Quality of Life in Indian Women after Vaginal Birth and Cesarean Section: A Pilot Study Using the EQ-5D-5L Descriptive System." BMC Pregnancy and Childbirth 18(1):1-13.

Martínez-Galiano, Juan, Antonio Hernández-Martínez, Julián RodríguezAlmagro, and Miguel Delgado-Rodríguez. 2019. "Quality of Life of Women after Giving Birth: Associated Factors Related with the Birth Process." Journal of Clinical Medicine 8(3):324.

Mousavi, Fatemeh, and Parisa Shojaei. 2021. "Postpartum Depression and Quality of Life: A Path Analysis." The Yale Journal of Biology and Medicine 94(1):85-94.

Muhammad, Nanda N., Hamzah Shatri, Zubairi Djoerban, and Murdani Abdullah. 2017. "Uji Kesahihan Dan Keandalan Kuesioner World Health Organization Quality of Life-HIV Bref Dalam Bahasa Indonesia Untuk Mengukur Kualitas Hidup Pasien HIV/AIDS.” Jurnal Penyakit Dalam Indonesia 4(3):112.

Nakamura, Yukako, Takashi Okada, Mako Morikawa, Aya Yamauchi, Maya Sato, Masahiko Ando, and Norio Ozaki. 2020. "Perinatal Depression and Anxiety of Primipara Is Higher than That of Multipara in Japanese Women." Scientific Reports 10(1):17060.

Papamarkou, Maria, Pavlos Sarafis, Charis P. Kaite, Maria Malliarou, Andreas Tsounis, and Dimitris Niakas. 2017. "Investigation of the Association between Quality of Life and Depressive Symptoms during Postpartum Period: A Correlational Study." BMC Women's Health 17(1):1-9.

Reay, Rebecca, Stephen Matthey, David Ellwood, and Maureen Scott. 2011. "Long-Term Outcomes of Participants in a Perinatal Depression Early Detection Program." Journal of Affective Disorders 129(1):94-103.

Rezaei, Nazanin, Fatemeh Janani, Nasibeh Sharifi, Fatemeh Omidi, and Arman Azadi. 2018. "Sexual Function and Quality of Life among Postpartum Women: A Cross-Sectional Study." International Journal of Women's Health and Reproduction Sciences 6(3):307-12.

Sadat, Zohreh, Masoumeh Abedzadeh-kalahroudi, and Mahboobeh Kafaei Atrian. 2014. "The Impact of Postpartum Depression on Quality of Life in Women After Child' s Birth." Iran Red Crescent Med J. 16(2):1-7.

Shitu, Solomon, Biftu Geda, and Merga Dheresa. 2019. "Postpartum Depression and Associated Factors among Mothers Who Gave Birth in the Last Twelve Months in Ankesha District, Awi Zone, North West Ethiopia." BMC Pregnancy and Childbirth 19(1):1-9. 
Silva, Catarine S., Marilia C. Lima, Leopoldina A. S. Sequeira- de- Andrade, Juliana S. Oliveira, Jailma S. Monteiro, Niedja M. S. Lima, Rijane M. A. B. Santos, and Pedro I. C. Lira. 2017. "Association between Postpartum Depression and the Practice of Exclusive Breastfeeding in the First Three Months of Life." Jornal de Pediatria (Versão Em Português) 93(4):35664.

Smorti, Martina, Lucia Ponti, and Federica Pancetti. 2019. "A Comprehensive Analysis of Post-Partum Depression Risk Factors: The Role of SocioDemographic, Individual, Relational, and Delivery Characteristics." Frontiers in Public Health 7:295.

Stewart, Donna E., and Simone N. Vigod. 2019. "Postpartum Depression: Pathophysiology, Treatment, and Emerging Therapeutics." Annual Review of Medicine 70:183-96.

Tungchama, F. P., C. G. Piwuna, A. Y. Armiya, Y. T. Maigari, and F. J. Davou. 2017. "Relationship between Quality of Life and Postpartum Depression among Women in North Central, Nigeria." Highland Med Res J 17(1):1118.

Winarni, Lastri Mei, Marthia Ikhlasia, and Rini Sartika. 2020. "Dampak Latihan Yoga Terhadap Kualitas Hidup Dan Psikologi Ibu Nifas." Jurnal Kebidanan Malahayati 6(1):8-16.

Zubaran, Carlos, and Katia Foresti. 2011. "Investigating Quality of Life and Depressive Symptoms in the Postpartum Period." Women and Birth 24(1):10-16. 